42

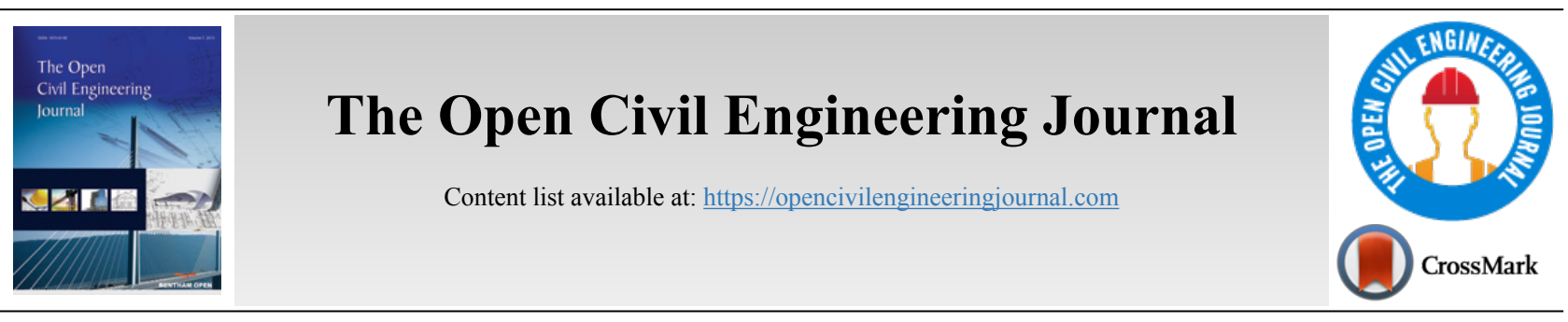

RESEARCH ARTICLE

\title{
Adequacy of the ASTM C1240 Specifications for Nanosilica Pozzolans
}

\author{
Maan S. Hassan ${ }^{*}$ \\ Civil Engineering Department, University of Technology, 10066, Baghdad, Iraq
}

\begin{abstract}
:
Background:

Nano-silica is a new pozzolan that is boosting the field of nanomaterials and can be used effectively in the concrete industry. ASTM C1240 is used to qualify silica fume pozzolans to be used in concrete and for marketing purposes.

Objective:

The present study aims to assess the adequacy of ASTM C1240 in qualifying nanosilica to be used in concrete and to introduce a modified procedure to measure the pozzolanic activity of nanosilica used with cementitious composites.

Methods:

The effects of various particle sizes and dosages on the compressive strength of blends in standard mortar were investigated. The correlation between the chemical reactivity and the compressive strength were also investigated using TGA and XRD analyses. The criterion conceived was validated at two ages: 7 days and 28 days.

\section{Results and Conclusion:}

The strength activity index results revealed that the following standard procedure ASTM C1240 is not applicable for nanosilica due to the high surface area and great pozzolanic reactivity of $\mathrm{SiO}_{2}$ nanoparticles, so a lower cement replacement percentage should be used. This study suggests that it should not be more than $7 \%$. The pozzolanicity testing results confirm that a nanosilica replacement level of more than $7 \%$ could not be effective in transforming further Portlandite into a C-S-H or other major cementing compound, leading to a "false negative" for nanosilica pozzolans.
\end{abstract}

Keywords: Nano-silica, Silica fume, ASTM C1240, Portlandite, Pozzolanic reaction, Strength activity index.

\begin{tabular}{|l|l|l|r}
\hline Article History & Received: December 10,2018 & Revised: January 30, 2019 & Accepted: February 11, 2019
\end{tabular}

\section{INTRODUCTION}

There is a growing interest across the globe in the use of Supplementary Cementitious Materials (SCMs) in concrete mixtures, and this interest has enhanced researchers in evaluating different forms of materials or other materials entirely to serve as suitable alternatives in SCMs [1 - 4]. The increase in the utilization of SCMs with concrete has led to a significant decrease in the world average percentage of clinker in the cement industry, decreasing from $85 \%$ in 2003 to $77 \%$ in 2010 with a further decrease expected in the future [5]. Materials such as natural pozzolans, fly ash, silica fume, ground granulated blast furnace slag, and ground glass are classified as SCMs.

\footnotetext{
* Address correspondence to this author at the Civil Engineering Department, University of Technology, 10066, Baghdad, Iraq; Tel: +964 7901151092; E-mails: 40018@uotechnology.edu.iq; maan_s_h@yahoo.co.uk
}

The International Standard (ASTM) C1240, Standard Specification for Silica Fume Used in Cementitious Mixtures [6], involves a sequence of tests that are used to decide if silica fume is suitable for use as SCMs in concrete. The main focus of this standard is to examine the reactivity of the silica fume using an oxide analysis and compressive testing. This is an indirect procedure to assess the pozzolanicity or hydraulic activity of the SCMs intended to be used with concrete. Regarding oversized particles, ASTM 1240 stipulates that the maximum percentage retained on 45- $\mu \mathrm{m}$ (No. 325) should not be more than $10 \%$, and the specific surface area must not be less than $15 \mathrm{~m}^{2} / \mathrm{g}$. However, the standard does not mention any minimum particle size limits. Regarding compressive strength testing, in ASTM 1240 the accelerated pozzolanic strength activity index is determined by comparing the compressive strength of mortar containing the material under evaluation with a control mortar at 7 days of age. Ten percent of the eva- 
luated mortar's cement is replaced with a silica fume by weight and the control mortar contains $100 \%$ cement. The batch proportions and water/cement ratio $(\mathrm{w} / \mathrm{cm}=0.48)$ of the control mortar are kept constant and a high range water reducer is added to hold the flow of the SCM-mortar within 100 to $115 \%$ of the control mortar. To satisfy the requirements of ASTM C1240, the compressive strengths of the SCM-mortars must be at least $105 \%$ of the control mortar at 7 days [6].

Recently, a wide-range of nanosized materials [7 - 11], such as nano- $\mathrm{SiO}_{2}$, nano- $\mathrm{TiO}_{2}$, nano- $\mathrm{Al}_{2} \mathrm{O}_{3}$, nano- $-\mathrm{Fe}_{2} \mathrm{O}_{3}$, etc., have been proved to be able to promote the hydration process of the tricalcium silicate (also known as alite, $\mathrm{C}_{3} \mathrm{~S}$ ) and cement, and improve the final performance of the cement based materials.

Nano-silica particles are amorphous materials with high purity and a specific surface area, and therefore have the great pozzolanic potential $[12,13]$. However, the pozzolanicity measurement procedure of such nano-silica materials has not yet been clearly established. Kong et al. [8] and Thomas et al. [14] imputed the nano-silica accelerating effects on the early hydration of $\mathrm{C}_{3} \mathrm{~S}$ and thus the immediate formation of the C-S$\mathrm{H}$ seeds from pozzolanic reaction between nano-silica and calcium hydroxide. This formation of C-S-H seeds is responsible for providing large amounts of reactive siliceous surface to serve as nucleation sites for early C-S-H precipitation, and the hydration is thus accelerated.

The ASTM C1240 test procedure is problematic for determining the pozzolanicity of nano-silica for many reasons. For instance, the replacement of the cement by weight with an SCM does not consider the fact that the density of the cement is significantly higher than that of most SCMs, resulting in a reduction of the water volume fraction $[13,15]$. Other researchers have utilized a $35 \%$ volumetric replacement of cement by pozzolans [15], thus taking the specific gravity of the SCM into account. Bentz et al. [15] and others [3, 13] stated that taking the densities of the SCMs into account is an important issue that can vary widely.

Another challenge of using nano-silica particles is the use of a varying the $\mathrm{w} / \mathrm{cm}$ ratio in the strength activity index test. The impact of the w/cm ratio on the mortar's compressive strength has been criticized because it can mask the impact of the materials tested $[15-18]$. Any adjustment of the w/cm ratio of an SCM mixture to achieve an equivalent flow to the control mixture can increase the water content of the mixture, which can occur with nano-sized particles. The increase in the water content typically results in a reduction in the compressive strength of the mixture. The use of water reducers, as mentioned in C1240, can help to partially achieve a standard consistency of the mixtures with a constant $\mathrm{w} / \mathrm{cm}$ ratio [16], but with a high replacement ratio of up to $10 \%$, it will be difficult to reach.

Another concern with the strength activity index test is that nano-silica, due to the very high surface area and possible deficiency in the $\mathrm{w} / \mathrm{cm}$ ratio, becomes a filler material at 7 days of age or even after. This "filler effect" could be eliminated through either an increase of the testing age to at least 28 days or reducing the replacement percentage values stated by $\mathrm{C} 1240$ to be below $10 \%$. However, the first option is difficult in practice as longer time is then required to complete the test.

This study tests the hypothesis that ASTM C1240 does not adequately qualify nano-silica pozzolans to be used in concrete. The main concern in this study is that ASTM C1240 has the potential to provide an "inapplicable procedure" for nano-silica materials. The tests outlined in ASTM C1240 were adjusted and performed to study the effects of various particle sizes and dosages on the compressive strength of blends in standard mortars. The criterion conceived was validated at two ages: 7 and 28 days.

\section{EXPERIMENTAL WORKS}

The experimental programme is designed to verify the applicability of ASTM C1240 to assess the pozzolanicity of nano-silica by comparing the chemical reactivity and the compressive strength performance of mortars modified with different particle sizes and dosages of silica-based SCM.

\subsection{Materials and Methods}

The Portland cement (OPC) used was type I conforming to ASTM C150 [19]. The micro-silica (mS) used was supplied from the Sika Company in a densified dry particle form, conforming to ASTM C1240 [6]. It was a grey amorphous submicron powder and was manually dispersed in the cement for each mortar mixture. The nanosilica (nS) used was supplied

Table 1. Composition and properties of cement, micro-silica and nanosilica.

\begin{tabular}{|c|c|c|c|}
\hline- & Cement & Micro-silica & Nano-silica \\
\hline Silicon dioxide $\left(\mathrm{SiO}_{2}\right): \%$ & $20 \cdot 7$ & $90 \cdot 65$ & 99.8 \\
\hline Calcium oxide $(\mathrm{CaO}): \%$ & $61 \cdot 89$ & $1 \cdot 22$ & - \\
\hline Aluminium oxide $\left(\mathrm{Al}_{2} \mathrm{O}_{3}\right): \%$ & $4 \cdot 61$ & $0 \cdot 02$ & - \\
\hline Ferric oxide $\left(\mathrm{Fe}_{2} \mathrm{O}_{3}\right): \%$ & $3 \cdot 35$ & $0 \cdot 01$ & - \\
\hline Sulfur trioxide $\left(\mathrm{SO}_{3}\right): \%$ & $2 \cdot 4$ & $0 \cdot 24$ & - \\
\hline Magnesium oxide $(\mathrm{MgO}): \%$ & $3 \cdot 05$ & $0 \cdot 01$ & - \\
\hline Loss on ignition: $\%$ & $2 \cdot 16$ & $2 \cdot 86$ & $\leq 1$ \\
\hline Lime saturation factor: $\%$ & $0 \cdot 87$ & $0 \cdot 48$ & - \\
\hline Specific gravity & $3 \cdot 1$ & $2 \cdot 3$ & - \\
\hline Colour & Grey & Grey & White \\
\hline
\end{tabular}


from Evonik Company in the form of a white dry powder with an average particle size of $<15 \mathrm{~nm}$ and a specific surface area of $200 \mathrm{~m}^{2} / \mathrm{g}$. It was vigorously dry mixed with cement for not less than $30 \mathrm{~min}$ to disperse the nanosilica particles and to ensure that a homogenies cementitious blend became ready to use. Table 1 shows the chemical composition and physical properties of the OPC, $\mathrm{mS}$, and $\mathrm{nS}$ used in this study. To achieve the desired flow by the ASTM C109 [20], a polycarboxylate-based high-range water-reducing admixture (HRWRA) conforming to ASTM C494 type F [21] was used.

The fine aggregate used for the mortars in this study was graded standard sand (silica content 99\%) [22], in a rounded form with a water content lower than $0.1 \%$. It was received in packaged bags of $25 \mathrm{~kg}$.

\subsection{Mixtures and Sample Preparation}

The mortar mixtures were mixed using an electrically driven mechanical mixer (Fig. 1a), following the mortar preparation procedure of ASTM C305 [23]. The control specimens were mixed with a 0.485 water-cementitious ratio $(w / \mathrm{cm})$ and a 2.75 sand-cementitious ratio $(\mathrm{s} / \mathrm{cm})$. The mixtures including $\mathrm{mS}$ and $\mathrm{nS}$ were made with 3, 5, 7 and $10 \%$ binder weight replacements. For the $\mathrm{mS}$ and $\mathrm{nS}$ contained mortars, the $\mathrm{mS}$ and $\mathrm{nS}$ powders were homogeneously stirred together with the dry cement prior to being placed in the mixer and adding the mixing water. To decrease the number of unknowns, the specimens were mixed into the control mixture with similar $\mathrm{w} / \mathrm{cm}$ and sand $/ \mathrm{cm}$ ratios. The reduction in flow levels caused by $\mathrm{mS}$ or $\mathrm{nS}$ was compensated by adding HRWRA, (Fig. 1b). Some mixtures, even with using an over-dosage of HRWRA (i.e., $>10 \%$ of binder weight), did not reach a desirable workability. These mixtures are marked and explained in Table 2 and discussed in the subsequent sections. For each studied mixture, six mortar cubes were prepared and tested for compressive strength according to ASTM C109 [20] at 7 and 28 days of age.
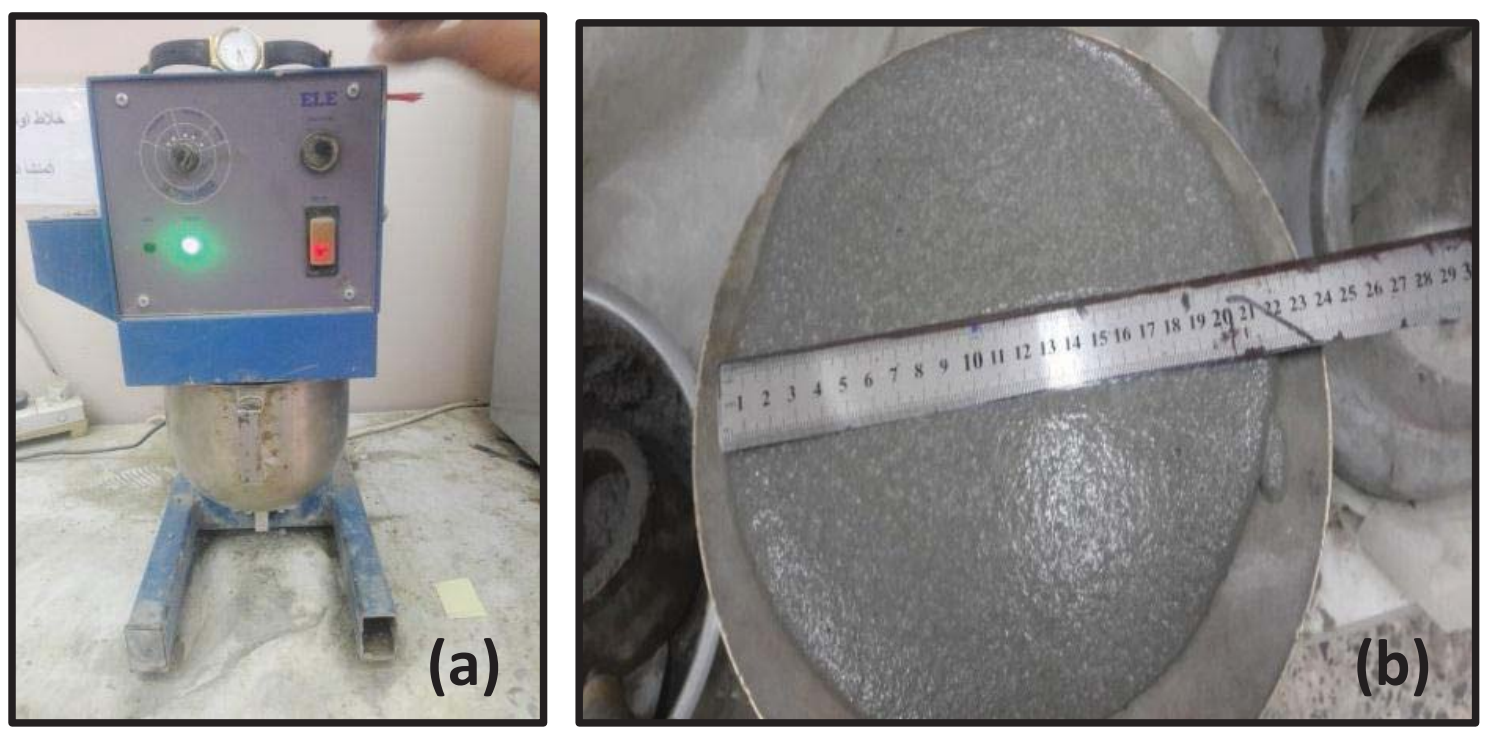

Fig. (1). Mortar mixing (a) and flow testing (b) facilities.

Table 2. Mixture proportion of mortars*.

\begin{tabular}{|c|c|c|c|c|c|c|}
\hline $\begin{array}{c}\text { Materials } \\
(\mathbf{g})\end{array}$ & Cement & Micro-silica & Nano-silica & $\begin{array}{c}\text { HRWRA } \\
(\% \text { of binder })\end{array}$ & $\begin{array}{c}\text { Flow } \\
(\%)\end{array}$ & $\begin{array}{c}\text { Passes ASTM } \\
\text { C1240 }^{* *}\end{array}$ \\
\hline $\mathrm{C}$ & 500 & 0 & 0 & $1(0.2)$ & 110 & yes \\
\hline $3 \mathrm{~m}$ & 485 & 15 & 0 & $1.5(0.3)$ & 110 & yes \\
\hline $5 \mathrm{~m}$ & 475 & 25 & 0 & $2(0.4)$ & 115 & yes \\
\hline $7 \mathrm{~m}$ & 465 & 35 & 0 & $2(0.4)$ & 100 & yes \\
\hline $10 \mathrm{~m}$ & 450 & 50 & 0 & $2.5(0.5)$ & 105 & yes \\
\hline $3 \mathrm{n}$ & 485 & 0 & 15 & $5(1)$ & 110 & yes \\
\hline $5 \mathrm{n}$ & 475 & 0 & 25 & $7.5(1.5)$ & 110 & yes \\
\hline $7 \mathrm{n}$ & 465 & 0 & 35 & $7.5(1.5)$ & 100 & yes \\
\hline $10 \mathrm{n}$ & 450 & 0 & 50 & $10(2)$ & 70 & no \\
\hline
\end{tabular}

For all mixtures: $\mathrm{w} / \mathrm{b}$ ratio $=0.485$, graded standard sand $=1375 \mathrm{~g}$ and binder $($ cement $+\mathrm{SCMs})=500 \mathrm{~g}$

"ASTM C1240 specifies that the flow values should be within the range of 100 to $115 \%$. 
All mortar cubes were hand-packed and compacted using an electromagnetic vibrating table. They were immediately plastic-wrapped and kept at room temperature of $23 \pm 3^{\circ} \mathrm{C}$ for a $24 \mathrm{~h}$, then placed in an airtight glass container and stored at $65^{\circ} \mathrm{C}$ for six days. Three cubes of each mixture were tested at 7 days after moulding and the other three cubes were stored in $100 \%$ moist curing until the testing age (28-day).

\section{ASTM STRENGTH AND POZZOLANICITY TESTS}

\subsection{Compressive Strength Testing}

Monitoring the compressive strength development of the mixtures containing $\mathrm{mS}$ or $\mathrm{nS}$ at a constant $\mathrm{w} / \mathrm{cm}$ ratio is important to observe the impact of the pozzolanic reaction on the compressive performance. However, to keep the mortar flow constant, the Accelerated Pozzolanic Strength Activity Index (APS) test in ASTM C1240 varies the percentages of HRWRA but not the w/cm ratio. This makes it possible to use the ASTM C1240 APS results to compare the effects of silicabased SCMs on the compressive strength of mortars. Unlike C618, C1240 requires an APS determination at 7 days only; in this study, the cubes were tested for compressive strength based on ASTM C109 at 7 and 28 days to assess the potential of filler effects, particularly for the nS-modified mortars.

\subsection{Pozzolanicity Tests}

As mentioned in many studies [1, 2, 24 - 26], many testing methods are available to determine the pozzolanicity of materials. In this research, two tests were used: the X-ray diffraction method (XRD) to quantify the amorphous supplementary cementitious materials in anhydrous and hydrated blended cements $[24,25]$ and portlandite $\left(\mathrm{Ca}(\mathrm{OH})_{2}\right)$ consumption in pastes measured using Thermal Gravimetric Analysis (TGA) $[1,2]$. This is because monitoring the consumption of portlandite by SCMs with time indicates the continuity of the pozzolanic reaction.

Upon reaching the testing age, the cubes were removed from the curing tank and put in a vacuum desiccator to stop the hydration process. The surfaces of the sample were first discarded as they could contain calcium hydroxide crystals that were oriented along the sample's outer surface. Next, slices of the hydrating mortars were cut at the set times of hydration and the hydration was stopped by solvent exchange in isopropanol for 7 days [24]. The samples were then ground to pass the No. 325 sieve $(45 \mu \mathrm{m})$ and placed back under a vacuum prior to testing to prevent carbonation of the materials. They were then finely measured by XRD.

The TGA testing was performed utilizing SHIMADZU equipment with an STA 60 simultaneous analysis system using $50-\mathrm{mg}$ samples and a dynamic nitrogen stream (flow rate $=30$ $\mathrm{mL} / \mathrm{min}$ ) to prevent carbonation of the material while the test was ongoing. The materials were heated up to $1000^{\circ} \mathrm{C}$ at a heating rate of $20^{\circ} \mathrm{C} / \mathrm{min}$. The samples were prepared in a similar manner to what was previously mentioned in the XRD examination and were dried at $60^{\circ} \mathrm{C}$ in an oven for $48 \mathrm{~h}$ and cooled to room temperature before performing the TGA analysis. The percentages of $\mathrm{P}$ per gram of mortar were quantified by converting the water loss during P decomposition. The ignited weight was normalized, and the percent of the tested mortar was determined. The degradation of $\mathrm{P}$ occurs typically between $400-500^{\circ} \mathrm{C}$ and these limits were used to find the start and end temperatures used to calculate the $\mathrm{P} \%$ values.

\section{RESULTS AND DISCUSSION}

\subsection{Strength Activity Index of Micro- and Nano-silica}

To measure the Accelerated Pozzolanic Strength Activity Index (APS) of the micro- and nanosilica, standard cement mortar samples were prepared and tested following the ASTM C1240 procedure. $3 \%, 5 \%, 7 \%$, and $10 \%$ replacements by weight of binder were evaluated and the results were compared with the control specimens (i.e., without micro- or nanosilica). The superplasticizer (HRWRA) content of the mixes was adjusted (Table 2 ) to obtain a spread flow of 100 to $115 \%$ to meet the minimum requirement of the $\mathrm{C} 1240$ and to ensure the desired rheological properties of the mixture. 5\% and $7 \%$ nanosilica mortars needed approximately 4 times the HRWRA than micro-silica mortars to exhibit a comparable spread flow. $10 \%$ nanosilica mortar did not meet the minimum C1240 flow requirements even when using $10 \mathrm{~g}(2 \%$ of the binder by weight) and still the result of this test was $25 \%$ lower than the minimum limits. This is mainly due to the high specific surface area of the nanosilica particles leading to capture more free water inside its structure, making it unavailable for the cement.
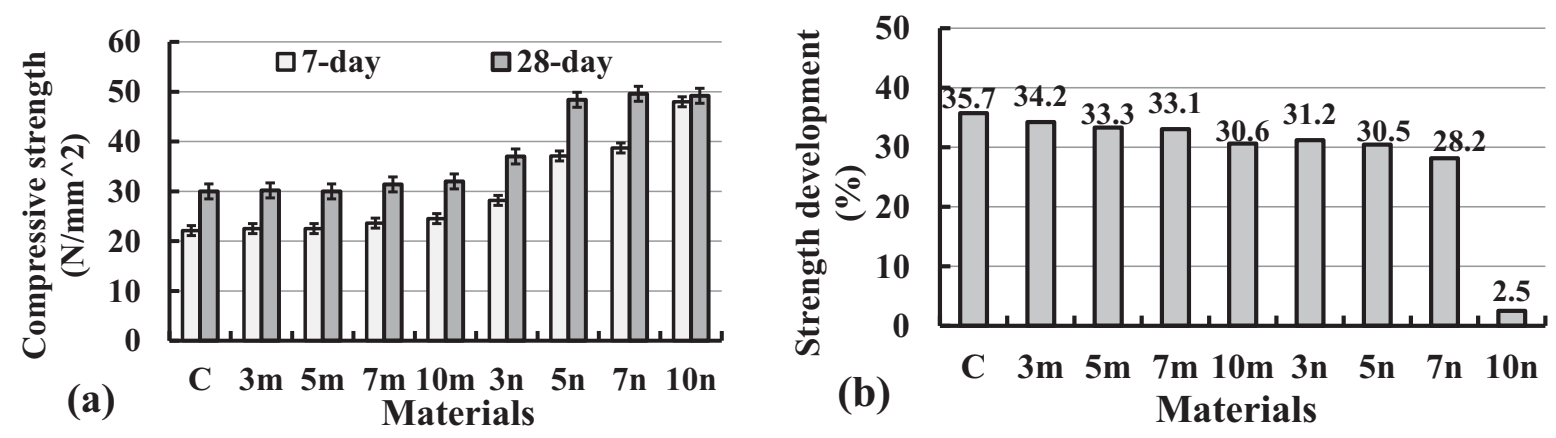

Fig. (2). Compressive strength results of the tested mortars, a) compressive strengths at 7 and 28 days and b) rate of development from 7 to 28 days. Error bars indicate standard deviation. 
After 7 and 28 days, the compressive strengths of the mixes were determined and the pozzolanic activity index was calculated based on the results of the tested standard cement mortar. The 7 days and, 28 days compressive strengths and the development in the strength results of the different mortars are shown in Fig. (2a). As can be observed, progressive increases in the nanosilica replacement level resulted in enhancements of the compressive strength of the studied mortars.

The 7 days compressive strength of the mortars with 3,5 , 7 , and $10 \% \mathrm{nS}$ replacement were $27,67,75$, and $117 \%$ more than that of the control mortar, respectively. At 28 days of age the same $\mathrm{nS}$ replacement mortars had 23, 61, 65, and 64\% more strength than the control mortar, respectively. These percent differences also suggest that there were progressive enhancements from increasing the $\mathrm{nS}$ replacement level. As seen from the percentages above, the enhancements for $10 \% \mathrm{nS}$ replacement at 7 days of age $(117 \%)$ were almost twice that of the 28 days (64\%), when compared to the control mortars.

A rate of strength development was calculated to compare how quickly different mortars modified with $\mathrm{mS}$ or $\mathrm{nS}$ gain strength compared to the control (Fig. 2b). This comparison allows for identifying the effect of the replacement levels on the speed of strength development (i.e., how much faster or slower the silica reacted). This comparison also removed the influence of OPC on the APS, as it is calculated as a percentage of the control mortars of each age. Fig. (2b) also shows that all mortars (except the $10 \% \mathrm{nS}$ mortar) have comparable strength developments from the 7 to 28 days rates. There was only a $7.5 \%$ difference between them. However, the $10 \% \mathrm{nS}$ replacement mixtures exhibited a reversal behaviour as opposed to their lower replacement counterparts. This trend shows that the 7 days accelerated curing suggested by the C1240 procedure cannot accurately describe the state of the strength at a later age when using a $10 \% \mathrm{nS}$ content. However, up to $7 \% \mathrm{nS}$ content, the development rates were seemed to be reasonable.
It is worth noting; the compressive strengths at both 7 and 28 days of the nanosilica mortar were higher than their microsilica counterparts. The lowest $\mathrm{nS}$ mortar outperformed the $\mathrm{mS}$ mortars even when compared with higher replacement levels.

It implied that the nano-silica particles can function as seeds for the growth of the C-S-H gels from the clinker hydration particularly at early ages [14].

The APS of the tested mortars were estimated using the 7 and 28 days compressive strengths (Fig. 3). In the case of $\mathrm{mS}$, there is a clear correlation between the APS values tested at 7 and 28 days. A progressive increase in the $\mathrm{mS}$ replacement level does not have significant impact on the APS values. There was only a $7.5 \%$ difference between them. This consistent behaviour supports the applicability of the C1240 procedure for the $\mathrm{mS}$ materials as the gain in strengths were kept the same regardless of the $\mathrm{mS}$ content or the testing age.

In contrast, the APS of the nS mortars show significant developments as the replacement levels increased and all of the $\mathrm{nS}$ mortars have a higher pozzolanic reactivity than their comparable $\mathrm{mS}$ mortars. Furthermore, with progressively higher replacement levels of $\mathrm{nS}$, the differences in the APS values observed between the two ages (i.e., 7 and 28 days) broadened, especially at the replacement level of $10 \%$. This implies that, at a lower replacement level up to $7 \%$, the gap between the two ages is not as apparent and the correlation between them is still reasonable. This difference becomes increasingly visible with higher replacement levels further than $7 \%$. Due to the similar chemical composition of the materials used in the fabrication of these mortars, it is reasonable to assume that the "filler effect" of $\mathrm{nS}$ had a more significant effect on controlling the gain in strength at later ages, when the replacement level passed a specific threshold value. This value is identified in this study to be more than $7 \%$. Moreover, the agglomerated state of the $\mathrm{nS}$ particles is another possible reason for such behaviour, suggesting that the maximum wet packing was not achieved, which led to a lower gain in strength in mortars with a rich $\mathrm{nS}$ content.

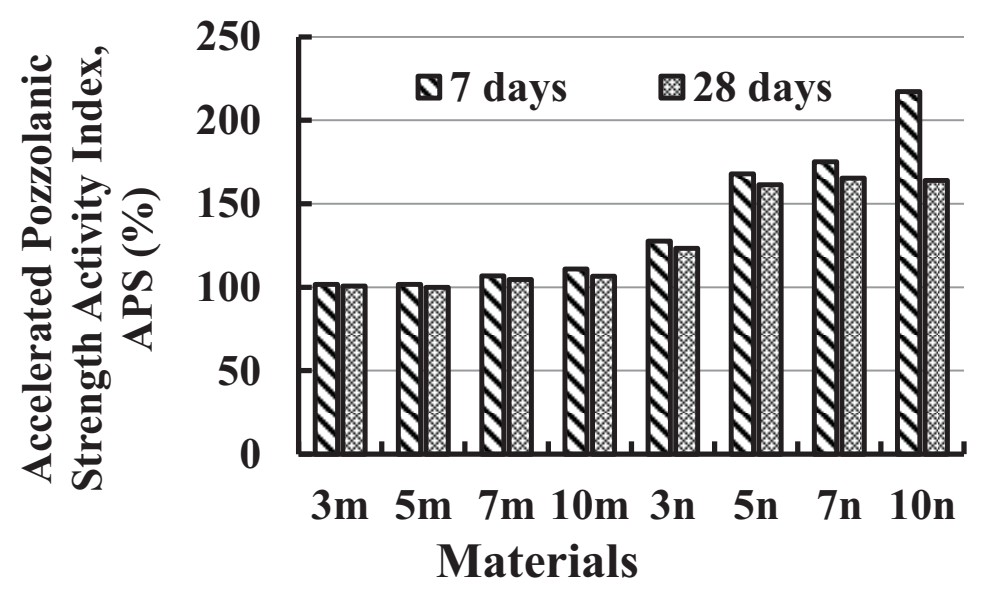

Fig. (3). Accelerated Pozzolanic Strength Activity Index of the different tested mortars. 

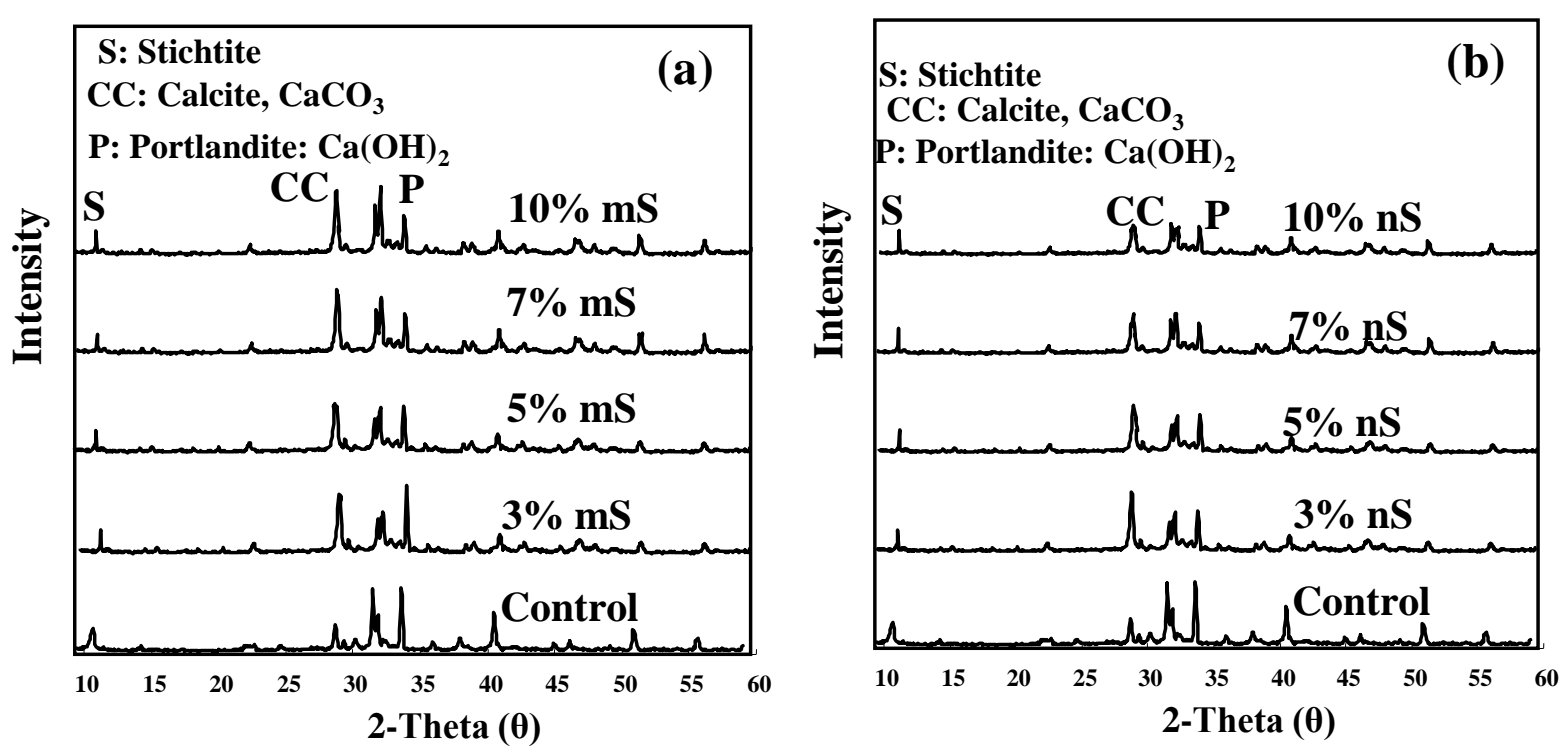

Fig. (4). XRD analyses of tested mortars at 28 days of age, (a) modified with $\mathrm{mS}$ and (b) modified with $\mathrm{nS}$.
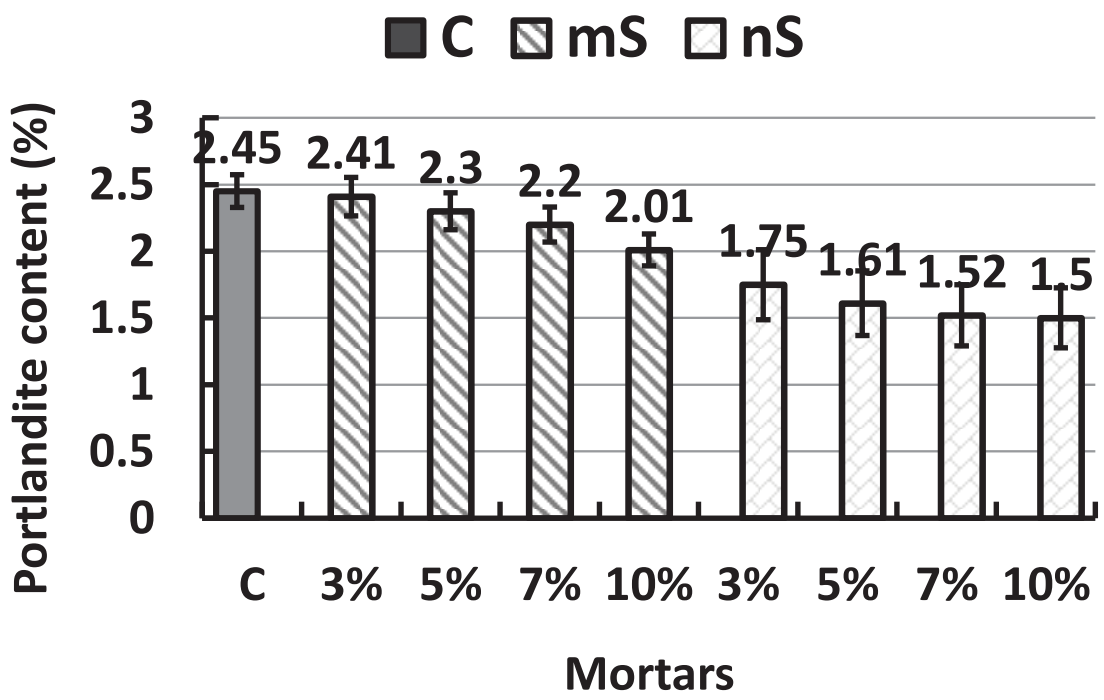

Fig. (5). $\mathrm{P}$ content (\% by weight) of control, $\mathrm{mS}$, and $\mathrm{nS}$ modified mortars at 28 days of age. Error bars indicate standard deviation.

\subsection{Pozzolanicity Testing}

\subsubsection{X-ray Diffraction (XRD)}

XRD diffractograms for the mortars modified with $\mathrm{mS}$ or $\mathrm{nS}$ as well as the control mortar are shown in Fig. (4). The consumption of Portlandite $\left(\mathrm{Ca}(\mathrm{OH})_{2}\right.$ or $\left.\mathrm{CH}\right)$ due to the cement replacement with $\mathrm{mS}$ (Fig. 4a) or $\mathrm{nS}$ (Fig. 4b) was first confirmed by XRD analyses performed at 28 days. In general, the diffractograms show that reflections assigned to Portlandite are reduced in all of the mortars modified with $\mathrm{mS}$ or $\mathrm{nS}$ compared with the control mortar. The higher the replacement level the greater the Portlandite consumption; and this consumption was more pronounced for mortars modified with nanosilica. In the case of micro-silica, 3\% mortars showed a comparable Portlandite level with the control mortars, whereas for $7 \%$ and $10 \%$ $\mathrm{mS}$ mortars the Portlandite was reduced by almost $50 \%$.
In contrast, the consumption of the Portlandite in the mortars modified with $\mathrm{nS}$ was more visible even with a low replacement level (i.e., 3\%). Mortars with 3, 5, 7, and 10\% nS replacement had 40,50,56, and 60\% less Portlandite consumption than the control mortar, respectively. The Portlandite consumption of the mortars with $\mathrm{nS}$ replacement showed that the nS-containing mortars all exhibited very similar levels of Portlandite reduction, indicating that higher levels of $\mathrm{nS}$ replacement are not necessarily proportionally beneficial. There is only a $4 \%$ observed improvement between $7 \%-\mathrm{nS}$ and $10 \%$-nS, meaning that a replacement level more than $7 \%$ could not be effective in transforming further Portlandite into a C-S$\mathrm{H}$ or other major cementing compound.

Therefore, the XRD testing suggests that the nanosilica powder has higher pozzolanic characteristics than a similar percentage of micro-silica powder does. Furthermore, replace- 
ments of 5 to $7 \%$ were identified as the optimum values to be used to test the pozzolanicity of the nanosilica materials. The results of the XRD testing agree well with the mortar compressive strength data.

\subsubsection{Thermal Gravimetric Analysis (TGA)}

The Portlandite content testing results using TGA are shown in Fig. (5) as the P content (\%) by mass of cement at 28 days of age. When the P content of an SCM containing mortar is lower than that of the control mortar, this means that a pozzolanic reaction has occurred [27]. The remarkably lower contents of the portlandite in the micro- and nanosilica modified mortars are again a reflection of the pozzolanic reactions [28]. However, the reductions were more pronounced in the nS mortars. It is also clear from Fig. (5) that the differences in the Portlandite reduction between 7 and $10 \% \mathrm{nS}$ mortars is less than $1.5 \%$, which confirming that a replacement level of more than $7 \%$ could not be effective in transforming further Portlandite into a C-S-H or another major cementing compound. Therefore, the extra amount of the employed nanosilica materials at more than $7 \%$ could only be helpful in enhancing the microstructure of the mortar by "filler effects" for the timeframe considered in this work. Once again, the results of the P content testing agree with the XRD data and the mortar compressive strength data.

\section{CONCLUSION}

The main focus of ASTM C1240 is to assess the suitability of silica fume for use in concrete. This assessment is also important in marketing the material in the concrete industry. After the emergence and evolution of the nanosilica, employing the same standard (i.e., C1240) for the qualification of nanosilica poses concerns due to the large differences in the surface area with various possible pozzolanicity reactions.

In this paper, the adequacy of ASTM C1240 in qualifying the nanosilica to be used in cementitious materials is tested, with the major concern being that this standard has the potential to provide misinterpretation for filler effects.

Based on the experimental programme results of this study, the following conclusions are drawn:

1- Fresh mortars with $10 \%$ nanosilica did not meet the minimum C1240 flow requirements even when using a high concentration of superplasticizer (i.e., $2 \%$ of the binder by weight). The results of this test were $25 \%$ lower than the minimum ASTM C1240 limits. This is mainly due to the high specific surface area of nanosilica particles leading to a higher capture amount of free water inside its structure, making it unavailable for the cement.

2- The compressive strength results clearly show that mortars made with up to $7 \%$ nanosilica have comparable strength developments from 7 to 28 days rates, with only a $7.5 \%$ difference between them. However, the $10 \% \mathrm{nS}$ replacement mixtures exhibited a reversal behaviour compared to their lower replacement counterparts. This trend demonstrates that the 7 days accelerated curing suggested by the $\mathrm{C} 1240$ procedure cannot accurately describe the state of strength in the later ages when using $10 \% \mathrm{nS}$ content. However, up to $7 \% \mathrm{nS}$ content the development rates seemed to be reasonable.

3- At a replacement level of up to $7 \%$, the difference in APS values observed between the two ages (i.e., 7 and 28 days) is not as apparent and the correlation between them is still reasonable. This difference becomes more and more visible with higher replacement levels more than $7 \%$. Due to the similar chemical compositions of the materials used in the fabrication of these mortars, it is reasonable to assume that the "filler effect" of $\mathrm{nS}$ had a more significant effect on controlling the gain in strength at later ages, when the replacement level passes a specific threshold value. This value is identified in this study to be $7 \%$.

4-The results of the Portlandite content testing revealed that a nanosilica replacement level more than $7 \%$ could not be effective in transforming further Portlandite into a C-S-H or other major cementing compound. Employing an extra amount of nanosilica therefore provides false negatives for a nanosilica materials test. This can lead to a low estimate of the true value of the APS. The results of the compressive strength testing, APS values and Portlandite content testing including XRD and TGA are consistent and assessed the materials similarly.

\section{CONSENT FOR PUBLICATION}

Not applicable.

\section{CONFLICT OF INTEREST}

The author declares no conflict of interest, financial or otherwise.

\section{ACKNOWLEDGEMENTS}

The author would like to thank the Civil Engineering Department of the University of Technology, Baghdad, Iraq, for extending their facilities for the above research work.

\section{REFERENCES}

[1] P. Suraneni, and J. Weiss, "Examining the pozzolanicity of supplementary cementitious materials using isothermal calorimetry and thermogravimetric analysis", Cement Concr. Compos., vol. 83, pp. 273-278, 2017

[http://dx.doi.org/10.1016/j.cemconcomp.2017.07.009]

[2] M.C.G. Juenger, and R. Siddique, "Recent advances in understanding the role of supplementary cementitious materials in concrete", Cement Concr. Res., vol. 78, pp. 71-80, 2015.

[http://dx.doi.org/10.1016/j.cemconres.2015.03.018]

[3] B. Alrashedi, and M. Hassan, "Effects of nano and micro size of clay particles on the compressive and tensile strength properties of selfconsolidating concrete", MATEC Web of Conferences, vol. 162, 2018 [http://dx.doi.org/10.1051/matecconf/201816202030]

[4] F. Avet, R. Snellings, A.A. Diaz, M. Ben Haha, and K. Scrivener, "Development of a new rapid, relevant and reliable (R3) test method to evaluate the pozzolanic reactivity of calcined kaolinitic clays", Cement Concr. Res., vol. 85, pp. 1-11, 2016.

[http://dx.doi.org/10.1016/j.cemconres.2016.02.015.]

[5] M. Schneider, M. Romer, M. Tschudin, and H. Bolio, "Sustainable cement production-present and future", Cement Concr. Res., vol. 41, no. 7, pp. 642-650, 2011.

[http://dx.doi.org/10.1016/j.cemconres.2011.03.019] 
[6] M. Schneider, M. Romer, M. Tschudin, and H. Bolio, "Sustainable cement production-present and future", Cement Concr. Res., vol. 41, no. 7 , pp. $642-650,2011$

[http://dx.doi.org/10.1016/j.cemconres.2011.03.019]

[7] I-W. Lee, J. Park, D.J. Kim, and S. Pyo, "Effects of abraded fine particle content on strength of quick-hardening concrete", Cement Concr. Compos., vol. 96, pp. 225-237, 2019.

[http://dx.doi.org/10.1016/j.cemconcomp.2018.12.004]

[8] D. Kong, S. Huang, D. Corr, Y. Yang, and S.P. Shah, "Whether do nano-particles act as nucleation sites for C-S-H gel growth during cement hydration?", Cement Concr. Compos., vol. 87, pp. 98-109, 2018.

[http://dx.doi.org/10.1016/j.cemconcomp.2017.12.007]

[9] A. Hussein, R. Al Anbari, and M. Hassan, "Toluene concentrations reduction by using photocatalytic coating methods for cementitious materials", MATEC Web Conf., vol. 162, p. 5003, 2018. [http://dx.doi.org/10.1051/matecconf/201816205003]

[10] A.H. Mahdi, R.H. Al Anbari, and M.S. Hassan, "Humidity effect on the photocatalytic activity of sustainable cement-based composites", Open Civ. Eng. J., vol. 12, no. 1, pp. 383-400, 2018. [http://dx.doi.org/10.2174/1874149501812010383]

[11] Y. Al-Najjar, S. Yeşilmen, A. Majeed Al-Dahawi, M. Şahmaran, G. Yildirim, M. Lachemi, and L. Amleh, "Physical and chemical actions of nano-mineral additives on properties of high-volume fly ash engineered cementitious composites", ACI Mater. J., vol. 113, no. 6, pp. 791-801, 2016

[http://dx.doi.org/10.14359/51689114]

[12] M. Heikal, A.I. Ali, M.N. Ismail, and S.A.N.S. Ibrahim, "Behavior of composite cement pastes containing silica nano-particles at elevated temperature", Constr. Build. Mater., vol. 70, pp. 339-350, 2014. [http://dx.doi.org/10.1016/j.conbuildmat.2014.07.078]

[13] M.S. Hassan, I.N. Gorgis, and A.A. Jaber, "Fresh and hardened properties of nanosilica and microsilica contained self-consolidating concretes", ARPN J. Eng. Appl. Sci., vol. 17, no. 17, pp. 5140-5150, 2017.

[14] J.J. Thomas, A.J. Allen, and H.M. Jennings, "Hydration kinetics and microstructure development of normal and $\mathrm{CaCl} 2$-Accelerated tricalcium silicate pastes", J. Phys. Chem. C, vol. 113, no. 46, pp. 19836-19844, 2009.

[http://dx.doi.org/10.1021/jp907078u]

[15] D. Bentz, "Comparison of ASTM C311 strength activity index testing versus testing based on constant volumetric proportions BT comparison of ASTM C311 strength activity index testing versus testing based on constant volumetric proportions", 2012

[16] S. Donatello, M. Tyrer, and C.R. Cheeseman, "Comparison of test methods to assess pozzolanic activity", Cement Concr. Compos., vol.
32, no. 2, pp. 121-127, 2010 .

[http://dx.doi.org/10.1016/j.cemconcomp.2009.10.008]

[17] S. Seraj, R. Cano, R.D. Ferron, and M.C.G. Juenger, "The role of particle size on the performance of pumice as a supplementary cementitious material", Cement Concr. Compos., vol. 80, pp. 135-142, 2017.

[http://dx.doi.org/10.1016/j.cemconcomp.2017.03.009]

[18] B. Lothenbach, K. Scrivener, and R.D. Hooton, "Supplementary cementitious materials", Cement Concr. Res., vol. 41, no. 12, pp. 1244-1256, 2011.

[http://dx.doi.org/10.1016/j.cemconres.2010.12.001]

[19] ASTM-C150, "Standard specification for portland cement", Annu. B. ASTM Stand., vol. 41, pp. 1-8, 2015.

[20] ASTM C109, "Standard test method for compressive strength of hydraulic cement mortars ( Using 2-in . or [ 50-mm ] cube specimens ) 1,", Chem. Anal., vol. C109/C109M - 11b, pp. 1-9, 2010.

[21] ASTM C494, "Standard test method for compressive strength of hydraulic cement mortars ( Using 2-in . or [ 50-mm ] cube specimens ) 1", Am. Soc. Test. Mater., pp. 1-9, 2015.

[22] ASTM C778-13, "Standard specification for sand", 65.198.187.10, vol. 14, pp. 1-3, 2014.

[23] ASTM C305, "Standard practice for mechanical mixing of hydraulic cement pastes and mortars of plastic consistency", ASTM lnternational, pp. 1-3, 20111.

[24] R. Snellings, A. Salze, and K.L. Scrivener, "Use of X-ray diffraction to quantify amorphous supplementary cementitious materials in anhydrous and hydrated blended cements", Cement Concr. Res., vol. 64, pp. 89-98, 2014.

[http://dx.doi.org/10.1016/j.cemconres.2014.06.011]

[25] P. Soroushian, J-P.P. Won, and M. Hassan, "Durability and microstructure analysis of $\mathrm{CO} 2$-cured cement-bonded wood particleboard", Cement Concr. Compos., vol. 41, pp. 34-44, 2013.

[http://dx.doi.org/10.1016/j.cemconcomp.2013.04.014]

[26] P. Soroushian, J-P. Won, and M. Hassan, "Durability characteristics of CO2-cured cellulose fiber reinforced cement composites", Constr. Build. Mater., vol. 34, pp. 44-53, 2012.

[http://dx.doi.org/10.1016/j.conbuildmat.2012.02.016]

[27] F. Massazza, "10 - pozzolana and pozzolanic cements", In: P.C. Hewlet, Ed., Lea's Chemistry of Cement and Concrete (Fourth Edition)., 1998. Butterworth-Heinemann Oxford, pp. 471-635.

[28] A. Korpa, T. Kowald, and R. Trettin, "Phase development in normal and ultra high performance cementitious systems by quantitative X-ray analysis and thermoanalytical methods", Cement Concr. Res., vol. 39, no. 2, pp. 69-76, 2009.

[http://dx.doi.org/10.1016/j.cemconres.2008.11.003]

\section{C) 2019 Maan S. Hassan.}

This is an open access article distributed under the terms of the Creative Commons Attribution 4.0 International Public License (CC-BY 4.0), a copy of which is available at: (https://creativecommons.org/licenses/by/4.0/legalcode). This license permits unrestricted use, distribution, and reproduction in any medium, provided the original author and source are credited. 